\title{
The Screening Methods for Locomotive Syndrome in the Elderly; an
}

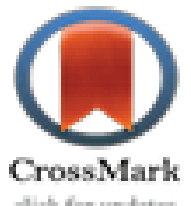

\section{Integrative Review}

\section{Sadeghi Mahalli N ${ }^{1}$, Hosseini $\mathrm{MA}^{2},{ }^{*}$ Nourozi K ${ }^{3}$}

1- Geriatric Nursing, MSc, University of Social Welfare and Rehabilitation Sciences, Tehran, Iran.

2-Associate Professor, Department of Rehabilitation, Faculty Member of University of Social Welfare and Rehabilitation Sciences, Tehran, Iran

3- Associate Professor, Nursing Ph.D. Faculty of Nursing, Nursing Department, University of Social Welfare and Rehabilitation Sciences. Tehran, Iran (Corresponding Author)

E.mail: Dr.kian_nourozi@yahoo.com

\section{Abstract}

Introduction: Elderly Demographic change will have a significant impact on societies. Locomotive disorders are common and important cause of disability and reduced quality of life in old age. Recognizing screening methods, can be early detection Locomotive syndrome (LS), prevented the incidence, prevalence and disability caused by this syndrome. The aim of this study is to integrative review of screening methods for LS in the elderly.

Method: In this review study, searches in international and national databases and journals: Science Direct, PubMed, Scopus, Irandoc, SID, with keywords Locomotive syndrome, Locomotive disorder, screening tool, assessment tool, physical performance test, from 2000 to 2018 were extracted and reviewed.

Results: From 70 related articles, 19 English articles were reviewed. Methods and tests used to assess, evaluate and LS screening in 19 Articles related to the purpose of this study include evaluation method of 9 - Physical and 3 questionnaire or Evaluation Checklist. These include: stand up test, one-leg standing test (with open eye), two-steps test, 5-times-sit-to-stand test, 6-walking time, the $10-\mathrm{m}$ gait time, measuring back muscles strength and grip strength, timed up-and-Go (TUG Test), maximum stride, self-check list (Loco-check), questionnaires GLFS-25 and GLFS-5.

Conclusion: In this study, screening methods of LS described. Because of the importance of the LS, using the perfect screening methods recommended in elders, for timely detection of LS.

Keywords: Locomotive Syndrome, Locomotive disorder, screening tool, assessment tool, physical performance test.

Received: 25 June 2019 Accepted: 1 September 2019

\begin{tabular}{|l|l|}
\hline \multicolumn{3}{|c|}{ Access this article online } \\
\hline
\end{tabular}




\section{روش هاى فربالَّرى سندرم حر كتى در سالمندان؛ مرورى يكِّار جهـ}

نسيم صادقى محلى'، محمدعلى حسينى"، قشيان نوروزى تبريزى"

1 - كارشناسى ارشد برستارى سالمندى، دانشكده برستارى، دانشكاه علوم بجزيستى و توانبخشى، تهران، ايران.

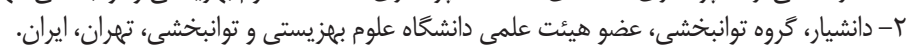

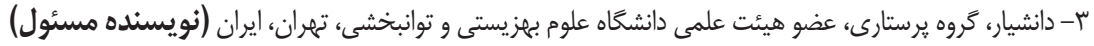
يست الكترونيكى: Dr.kian_nourozi@yahoo.com

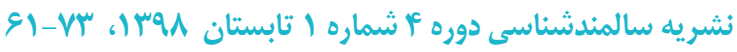

مقدمه: افزايش جمعيت سالمندان تأثير زيادى روى جوامع مى كذارد. بيمارى هاى حركتى از دلايل شايع و مهمم ناتوانى و كاهش

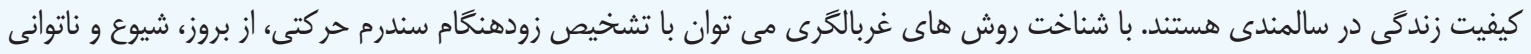

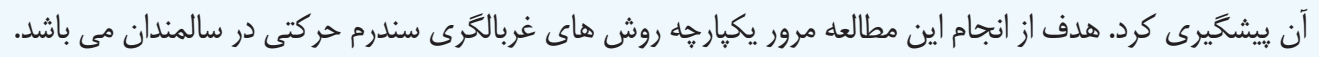

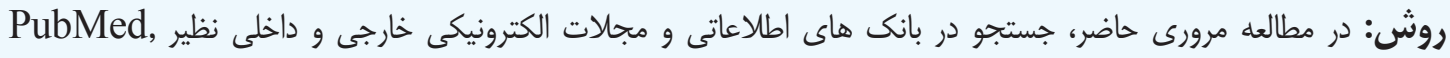
Scopus، Irandoc, SID, Science direct

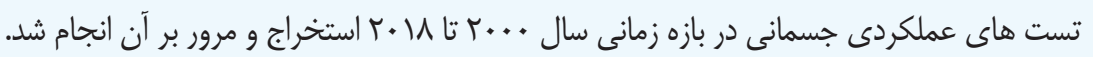

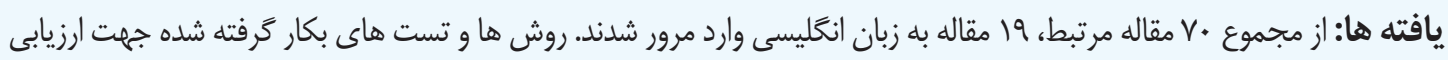
و غربالكرى سندرم حركتى در 19 مقاله مرتبط با هدف يزوهش، شامل 9 روش ارزيابى عملكردى - جسمانى و ؟ّ يرسشنامه بوده است. اين

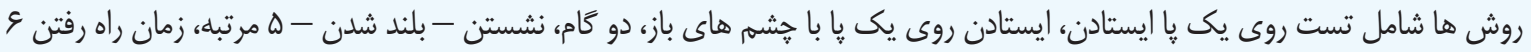

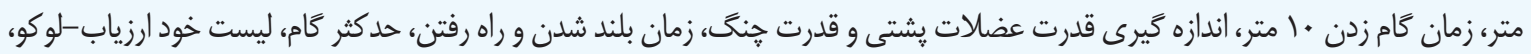

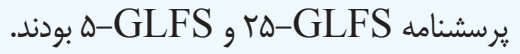

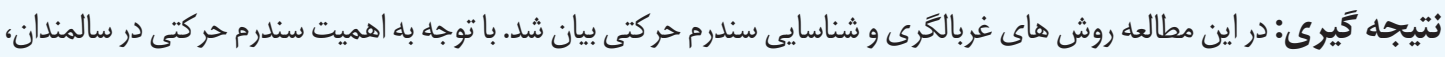

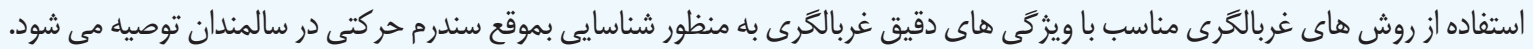

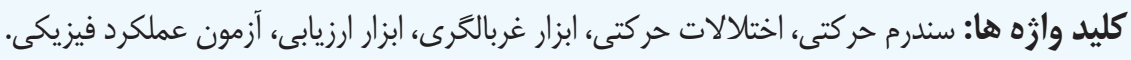

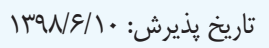

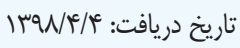

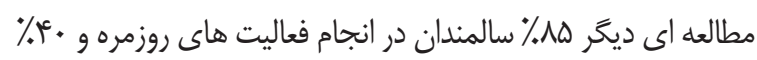
مقلdمه

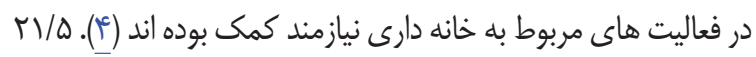

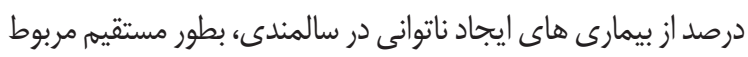

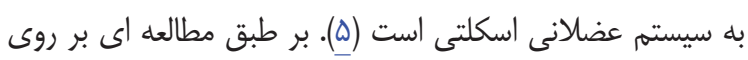

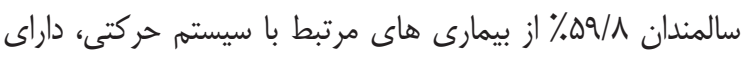
علل غير ترماتيك بودند كه شايع ترين آنها به ترتيب: دزنراسيون

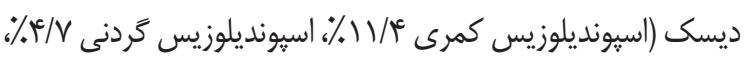

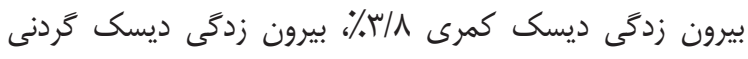
1\%) و تخريب غضروفى اندامهاى تحتانى (OA زانو

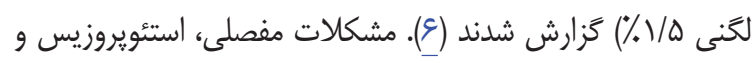

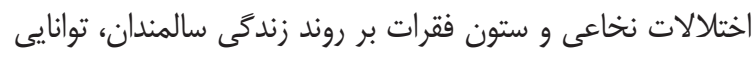

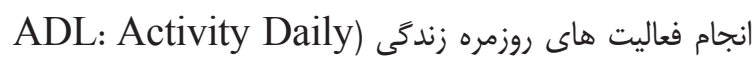
افز ايش جمعيت سالمندان، تاثيرات مختلف و زيادى بر جامعه

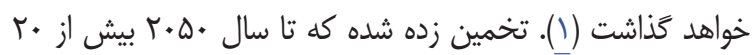
درصد جمعيت كل دنيا را افراد بالاى ه سال تشكيل دهند، در ايران هم ييش بينى شده كه جمعيت سالمندان كشور تا سال •ه •r، ه برابر

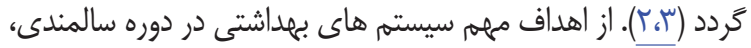
افزايش طول عمر به همراه افزايش توانايى و كيفيت زندگى سالمند ناتوانى يكى از ييامدهاى سالمندى مى باشد. بر طبق مطالعه اى يك سوم سالمندان دهار ناتوانى هاى شناختى بوده و • ع\% آنها به كمك هايى در فعاليت هاى روزمره همجيون نظافت، حركت، بلند كردن اجسام، خريد و حمل و نقل نياز داشته اند. در 
با توجه به شيوع بالاى اختلالات سندرم حركتى در دوره

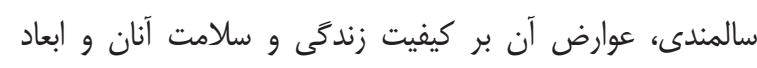
اجتماعى و اقتصادى جامعل غربالكرى اين اختالال در سالمندان

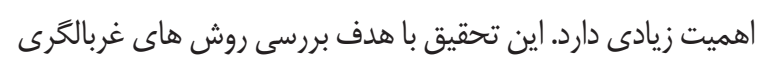

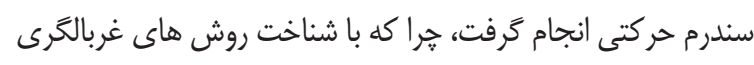

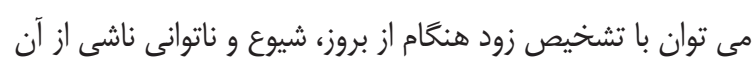
ييشخيرى كرد.

\section{روش مطالعها}

مطالعه حاضر از نوع مرورى يكيارجه است كه به مدت دون

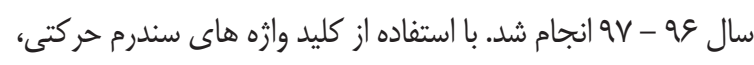

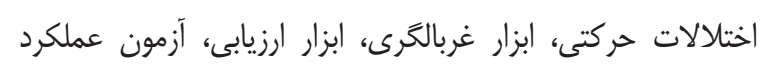

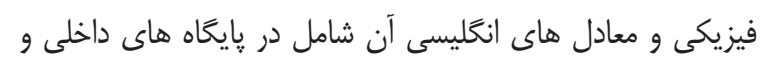

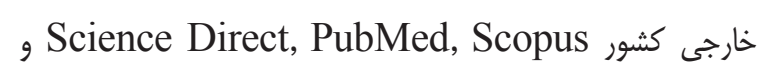
بانك هاى اطلاعاتى داخل كشور نظير Irandoc, SID, جست

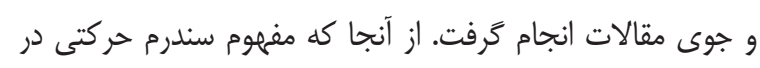

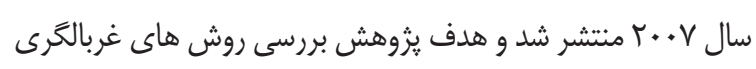

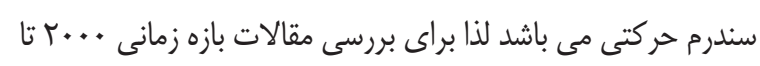

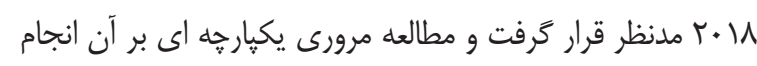

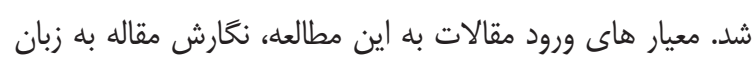

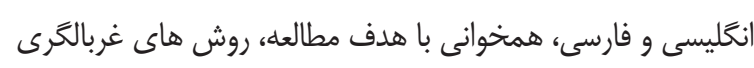

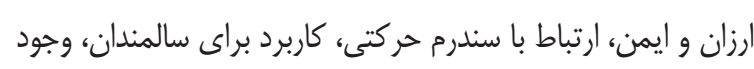

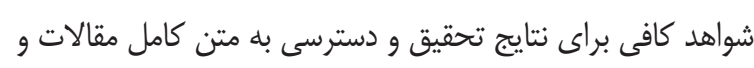

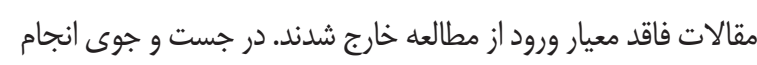

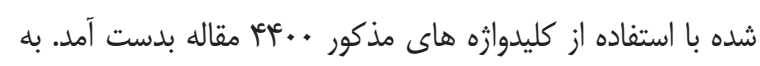

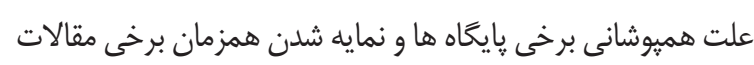

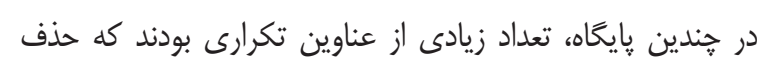

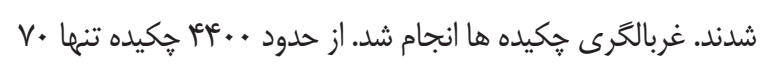
جكيده در راستاى مفهوم سندرم حركتى بود، در همين مرحله عناوين

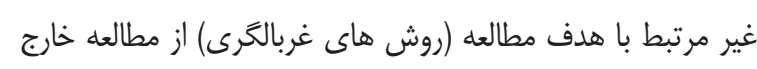

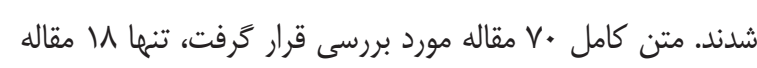

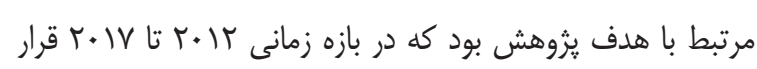

$$
\text { مى كرفت. (نمودار () مليط }
$$

Living و كيفيت زندكَيشان اثر بسيار زيادى خواهد كذاشت

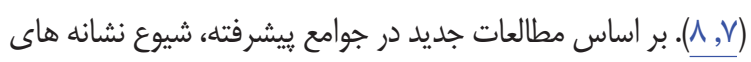

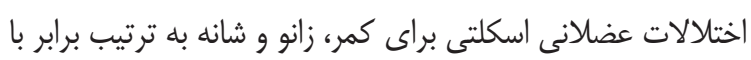

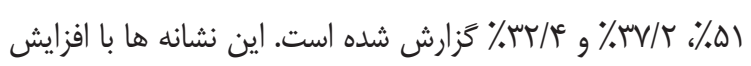
سن شيوع بيشترى مى يابد (9).

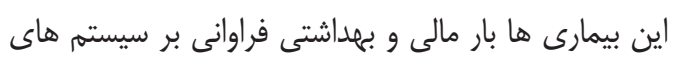

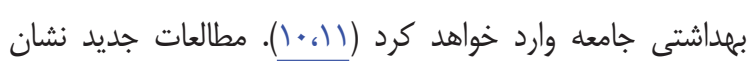
مى دهد با شيوع بيمارى هاى عضلانى اسكلتى در جمعيت سالمندان ابعاد مختلف كيفيت زندگى در جمعيت آنها كاهش مهى يابد. نتايج

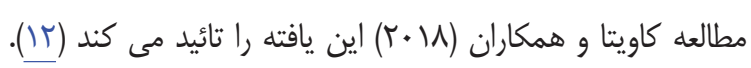

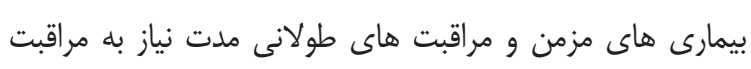

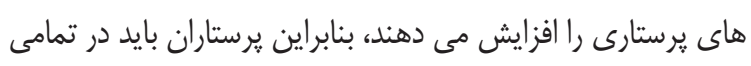
جنبه ها خود را براى مقابله با خالش هاى سلامتى سالمندان آماده

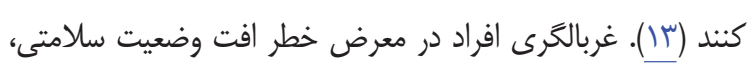

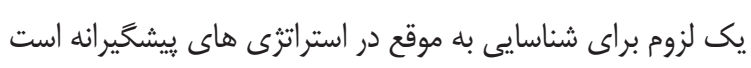

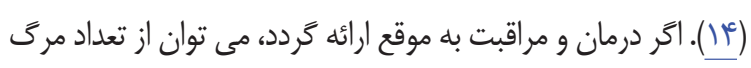

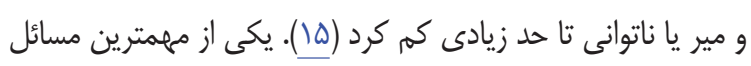
كه در مطالعه و بررسى ييامدهاى عملكردى در سطوح مختلف در

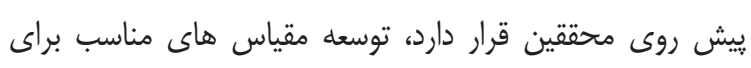

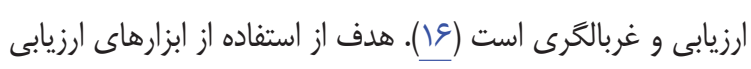

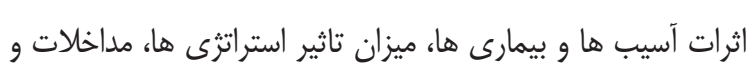
برنامه هاى درمانى و توان بخشى، بررسى سير ييشرفت سالمندان حها

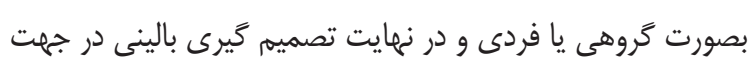
ادامه، توقف و يا اصلاح اين اقدامات مورد ارزيابى قرار مى كيرد.

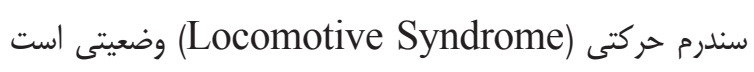
كه به علت اختلال در يكى از اركان هاى سيستم حركتى (عضلات،

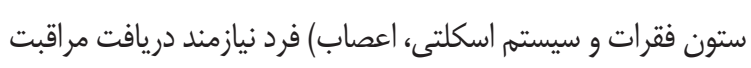

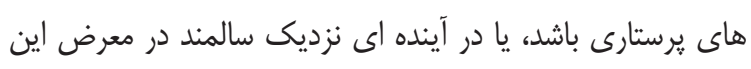

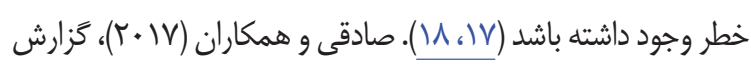
مى كنند كه سندرم حركتى در سالمندان كشور احتياج به توجه ويثه

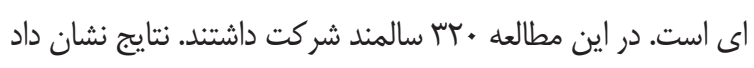

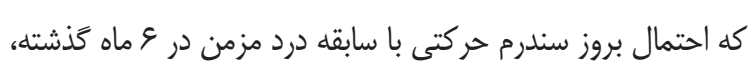

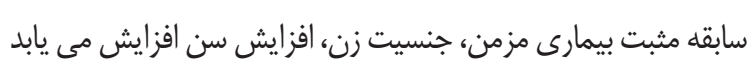

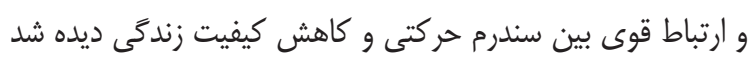

$(19.6 \cdot)$ 


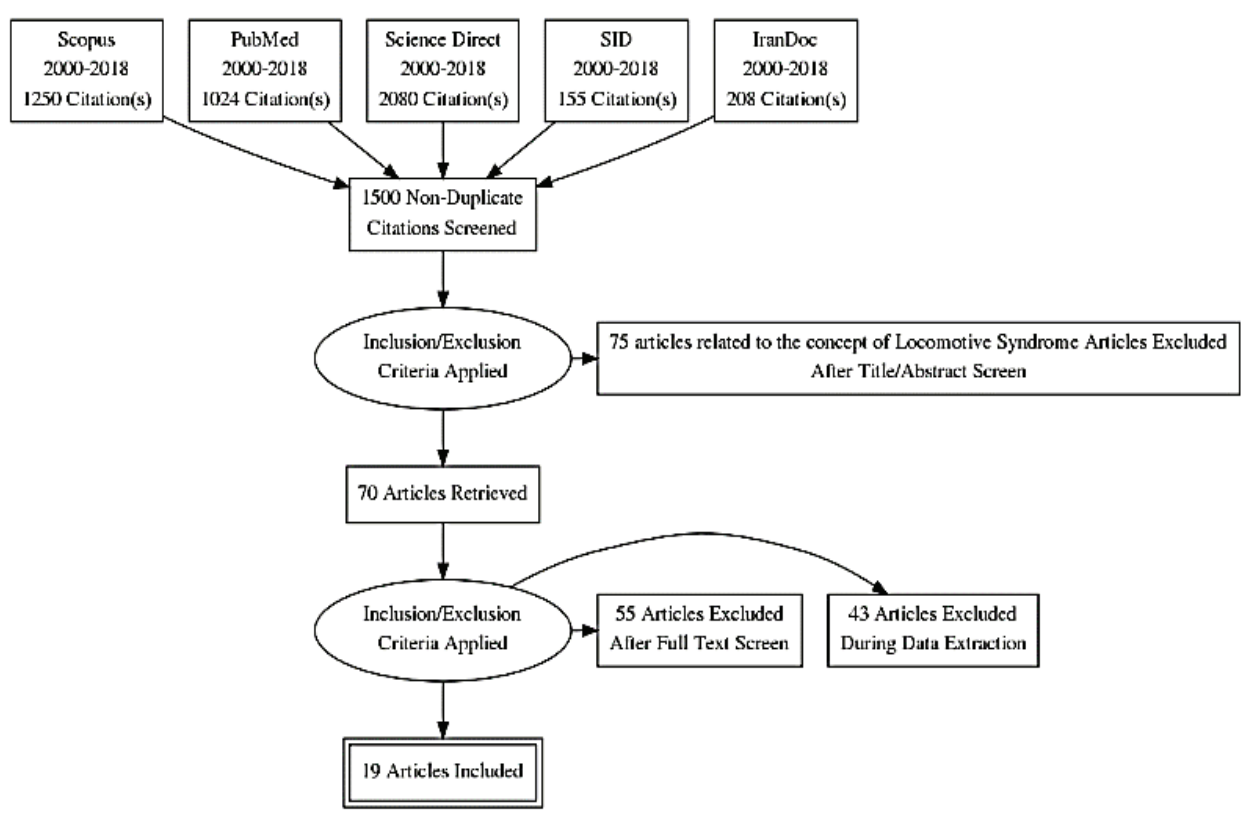

\section{نمودار (: دياكرام PARISMA سندرم حركتى}

يافْته ها

در مطالعه كنونى، 19 مطالعه به زبان انخَليسى مطابق با هدف يزوهش مورد تجزيه و تحليل قرار كرفتند. هيج مطالعه اى در زمينه

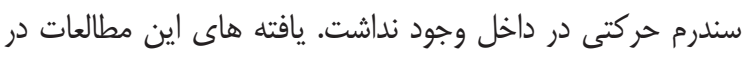
سه دسته اصلى ابزارى هاى غربالخرى عملكردى - جسمانى و

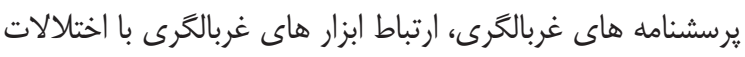

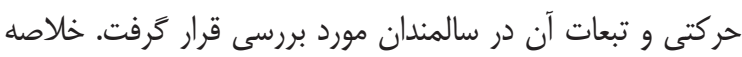
مطالعات منتخب براساس خى ليست ڤريزما، در (جدول () ارائه شد.
ملاحظات اخلاقى بر اساس دستورالعمل اخلاقى كوكران براى مطالعات مرورى: اين مطالعه در هيج كدام از نسخه هاى نشريه به خاب نرسيده است. تمامى نتايج تحقيق، بطور صادقانه، دقيق و به زبانى ساده منتشر شد. همجنين به تمام حقوق مادى و معنوى تيم تحقيق و تمامى افراد دست اندركار در يزوهش احترام گذاشته شد. از هرگونه سرقت ادبى يرهيز شد. مشاركت و توافق همكاران تحقيق بررسى و تائيد شد (r).

جدول (: مشخصات و يافته هاى مقالات وارد شده

\begin{tabular}{|c|c|c|c|c|c|c|}
\hline 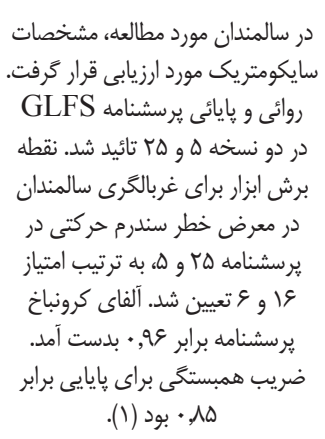 & III سالمندان & توصيفى -مقطعى (ابزار & يرسشنامه غربالحرى & 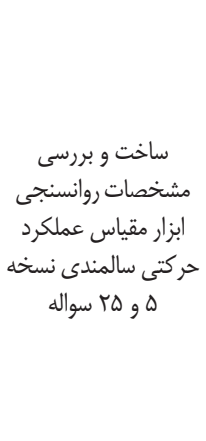 & 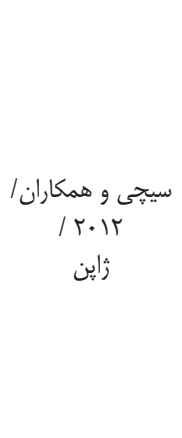 & 1 \\
\hline
\end{tabular}




\begin{tabular}{|c|c|c|c|c|c|c|}
\hline 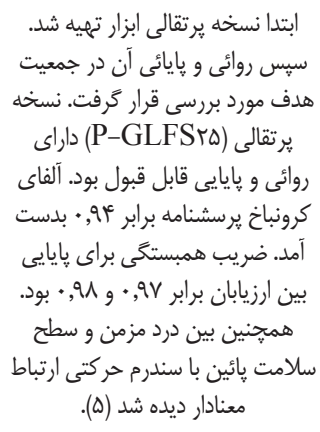 & سالمندان & توصيفى - مقطعى & 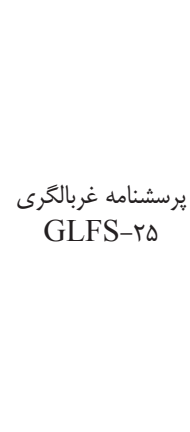 & 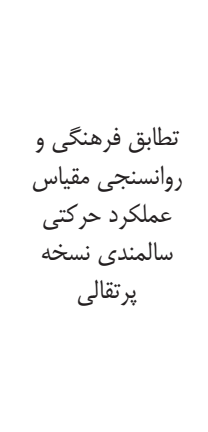 & 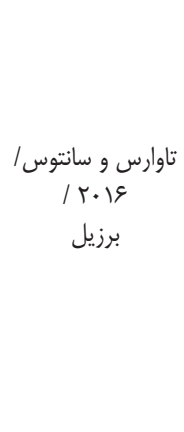 & $r$ \\
\hline 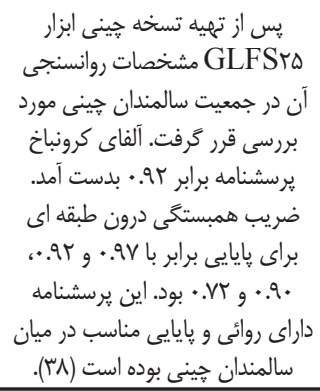 & سالمندان & توصيفى - مقطعى & 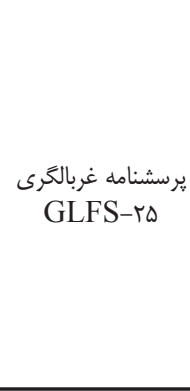 & 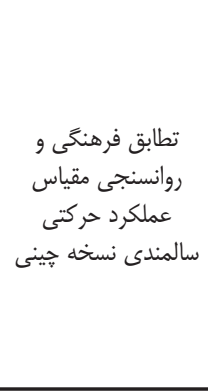 & 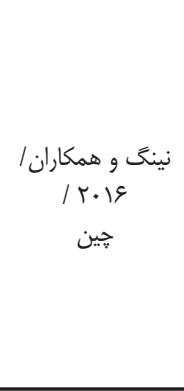 & $\mu$ \\
\hline 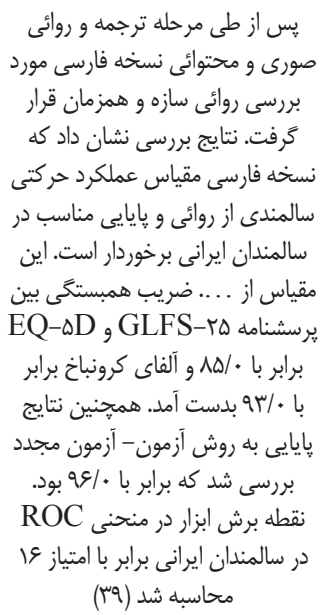 & •r ش شالمند داراى & توصيفى - مقطعى & 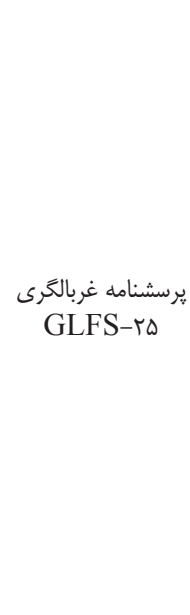 & 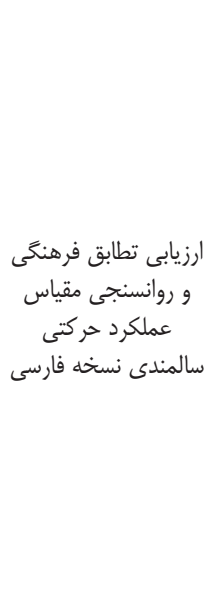 & 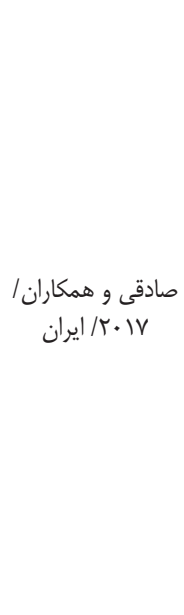 & $\varphi^{c}$ \\
\hline 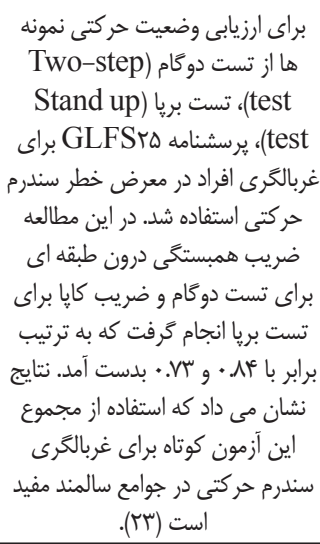 & $\begin{array}{l}\text { WV } \\
\text { سالمندان }\end{array}$ & مقطىى - توصيفى & 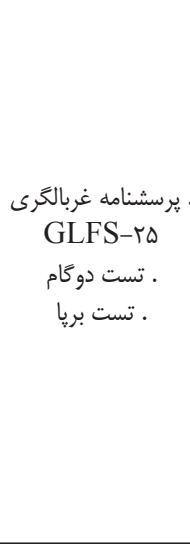 & 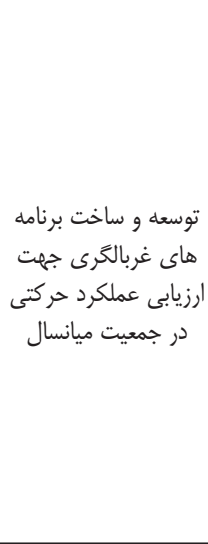 & 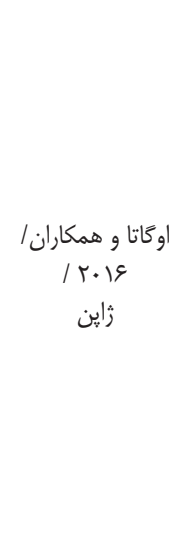 & $\Delta$ \\
\hline
\end{tabular}




\begin{tabular}{|c|c|c|c|c|c|c|}
\hline 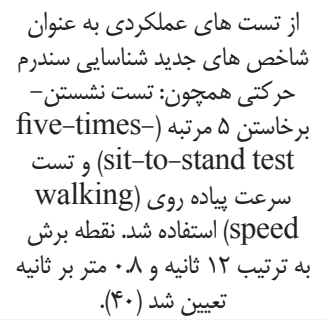 & 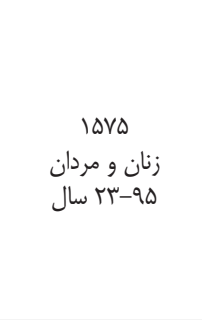 & توصيفى - مقطعى & ـ ـ سرعت يِياده روى - نشستن & 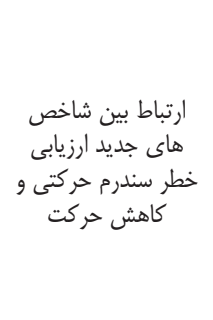 & 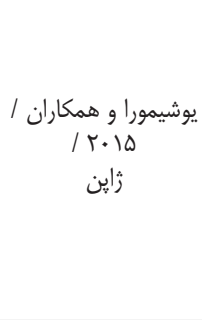 & 9 \\
\hline 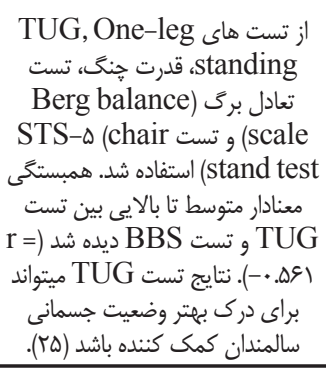 & $\begin{array}{l}19)^{6} \\
\text { سالمندان }\end{array}$ & توصيفى - مقطعى & 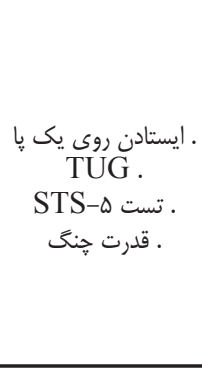 & 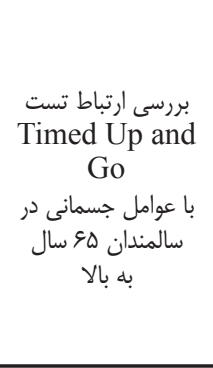 & 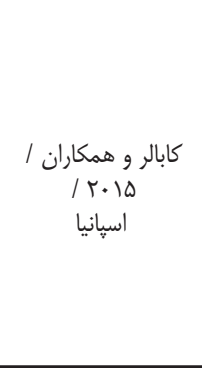 & v \\
\hline 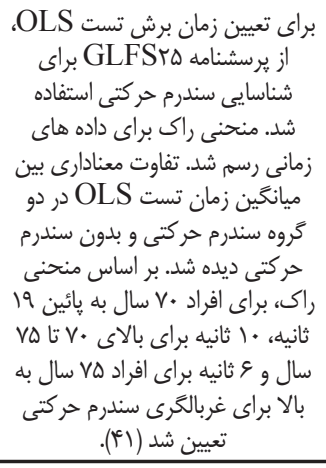 & $M$. & توصيفى مقطعى & & 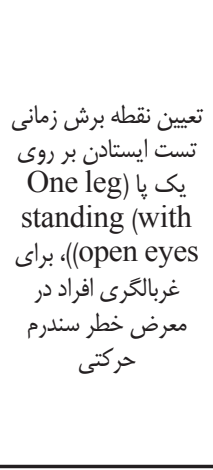 & 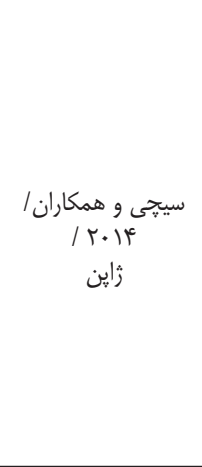 & $\wedge$ \\
\hline 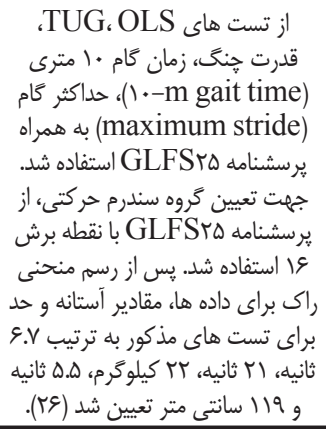 & $\begin{array}{l}\text { سالمندان } \\
\text { f. }\end{array}$ & توصيفى مقطعى & & تعت عملكرد فييزينى مقادير آستانه & 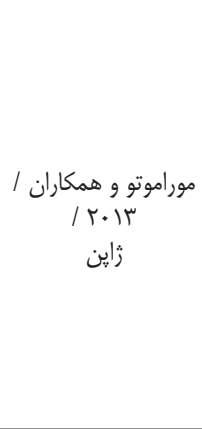 & 9 \\
\hline 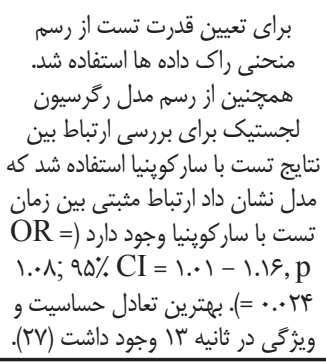 & زبان سالمندان & توصيفى-تحليلى & & 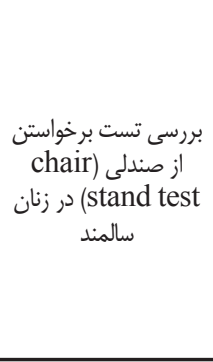 & 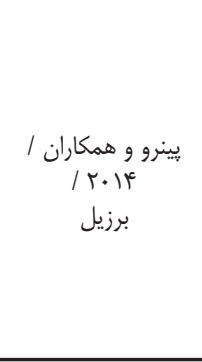 & 1. \\
\hline 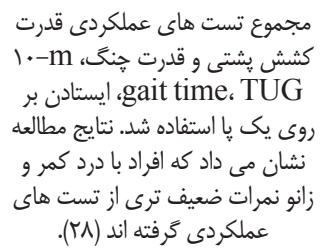 & ز زنان و مردان •ه سال & توصيفى-تحليلى & & $\begin{array}{c}\text { اثر درد كمر و زانو بر TUG } \\
\text { TUت }\end{array}$ & 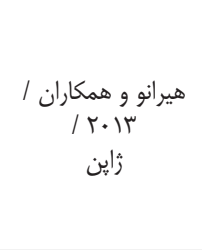 & 11 \\
\hline
\end{tabular}




\begin{tabular}{|c|c|c|c|c|c|c|}
\hline 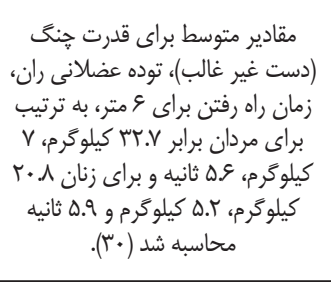 & 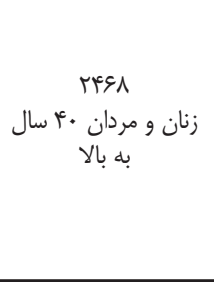 & توصيفى -مقطعى & & 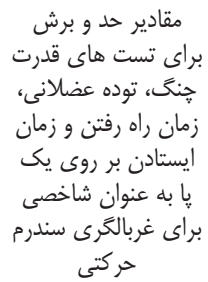 & 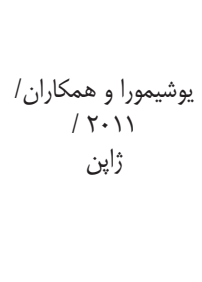 & 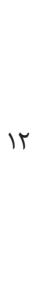 \\
\hline 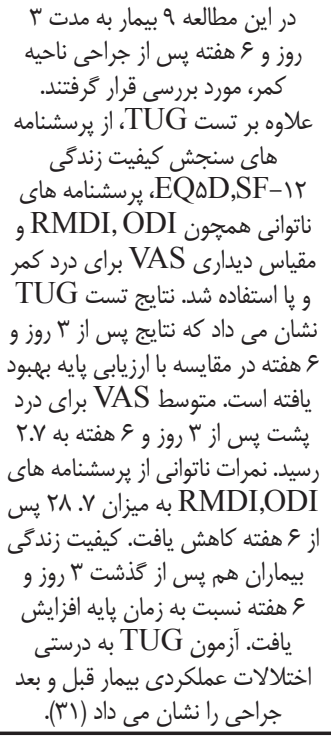 & 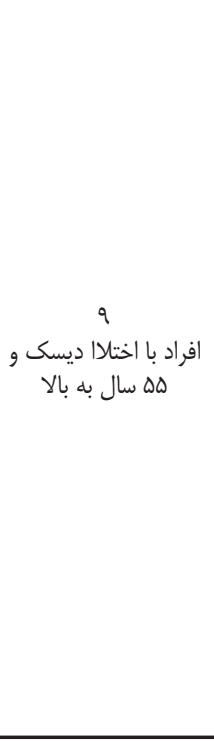 & آينده نكَر & TUG & درثن بيماران با اختلال برلى ديسى & 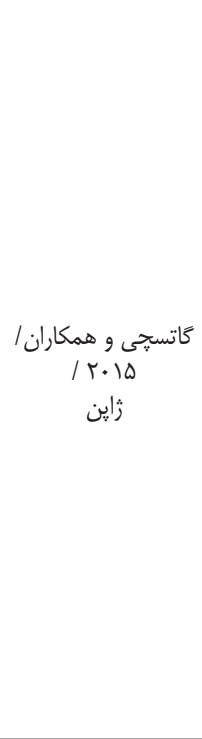 & rו \\
\hline 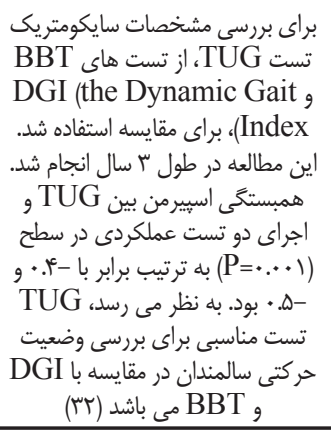 & $\begin{array}{l}\text { سالمندان } \\
\text { س }\end{array}$ & توصيفى آينده نكر - & $\begin{array}{l}\text { TUG } \\
\text { BBT } \\
\text { DGI }\end{array}$ & 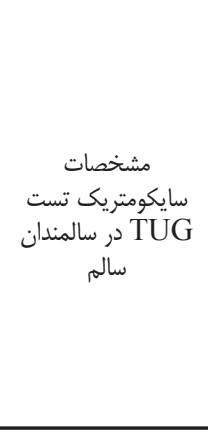 & • هرمان و همكاران/ اسرائيل & if \\
\hline 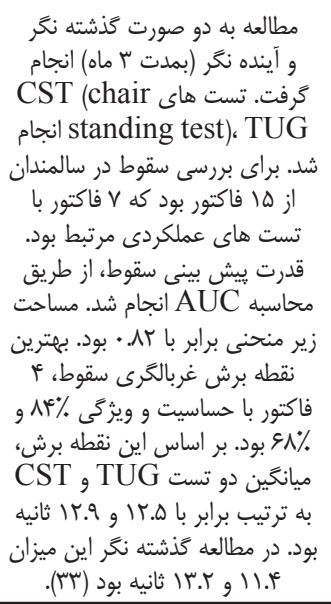 & 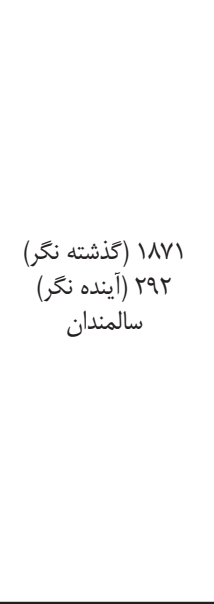 & 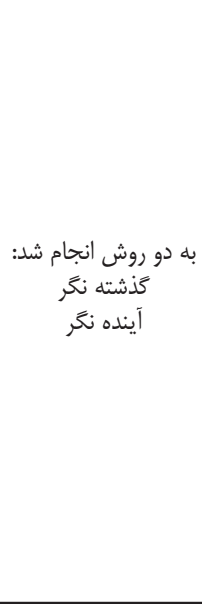 & $\begin{array}{l}\text { CST. } \\
\text { TUG . }\end{array}$ & 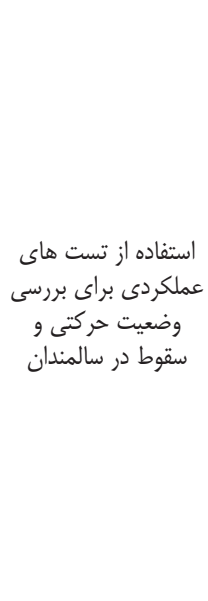 & 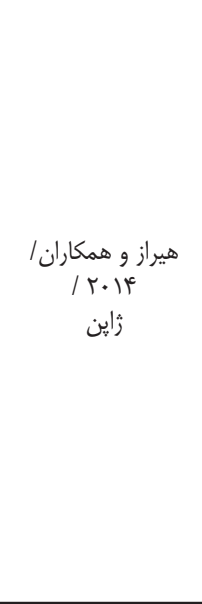 & 10 \\
\hline
\end{tabular}




\begin{tabular}{|c|c|c|c|c|c|c|}
\hline 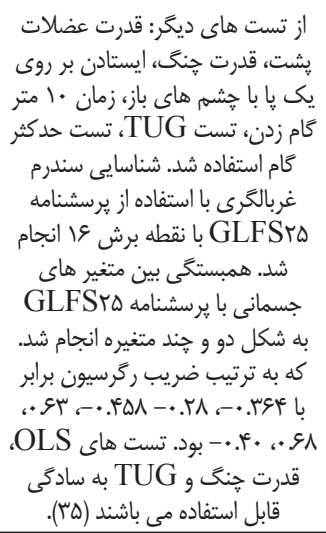 & $\begin{array}{c}\text { سالمندان } \\
\text { سه }\end{array}$ & توصيفى - مقطعى & 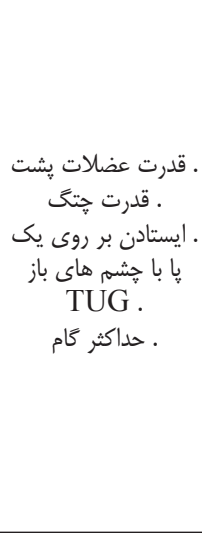 & و عملكر هاى براى جسمانى - ترزيى & 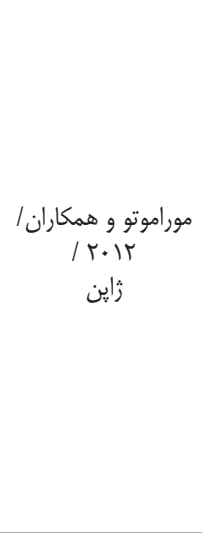 & 19 \\
\hline 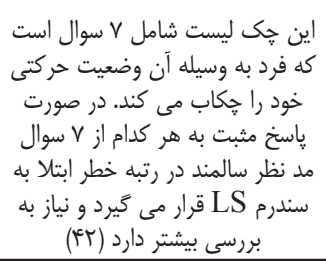 & $\begin{array}{l}\text { سالمندان } \\
\text { VT }\end{array}$ & توصيفى - تحليلى & . جى ليست لوكو - & 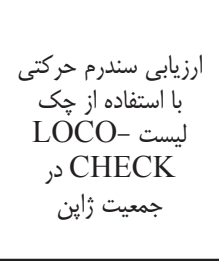 & 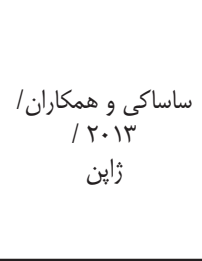 & IV \\
\hline 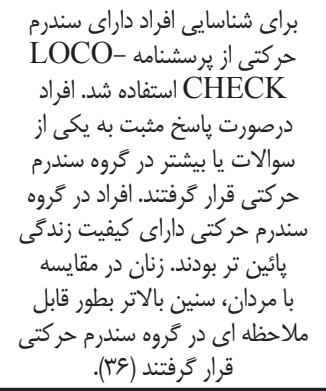 & 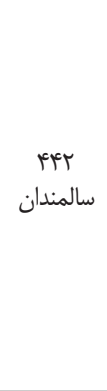 & توصيفى - تحليلى & . جى ليست لوكو - & 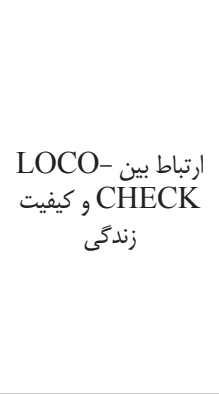 & 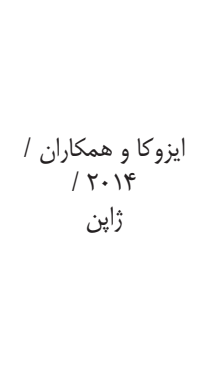 & 11 \\
\hline 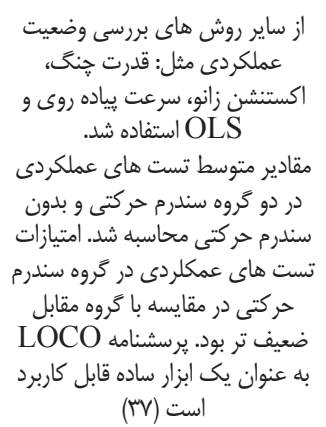 & 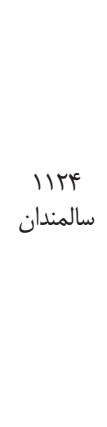 & توصيفى - مقطعى & 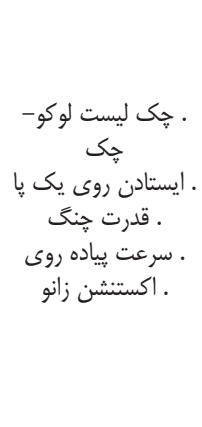 & 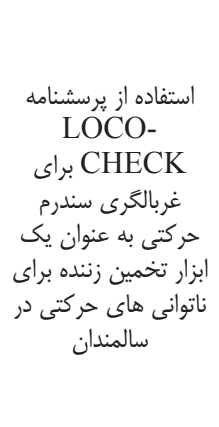 & 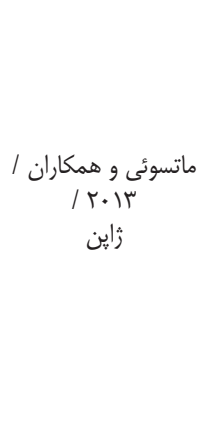 & 19 \\
\hline
\end{tabular}

برخيزد تست او رد خواهد شد.

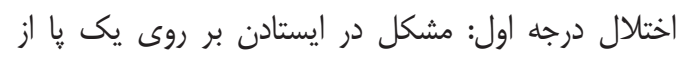

$$
\text { جهاريايه •t سانتى. }
$$

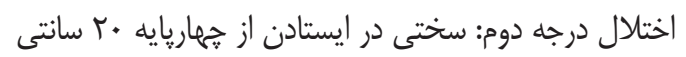

$$
\text { با هر دو يا (IV.rT). ( }
$$

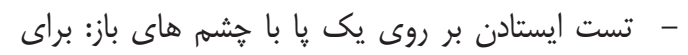

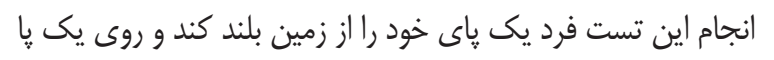
بايستد. دستانش را بر روى لخن خود قرار دهد. براى محاسبه زمان از كورنومتر استفاده مى شود. زمان تا زمان عدم برخورد يا بر زمين بردين

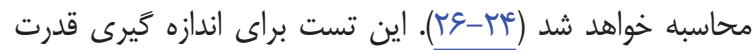

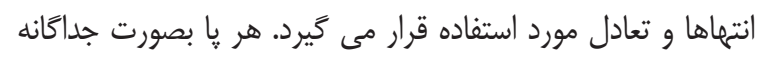

كليات مطالعات بر اساس سه هدف كلى مورد بررسى و توصيف قرار گرفتند كه در ّا بخش به بررسى آن مى يردازيه. 1- ابزارى هاى غربالخرى عملكردى -جسمانى:

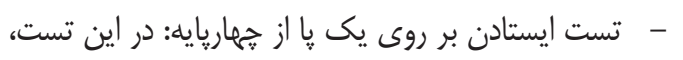

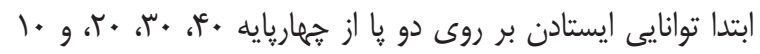

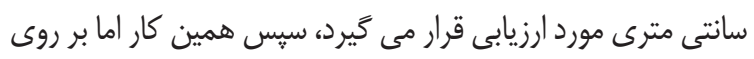

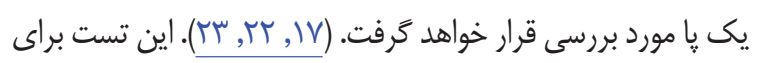

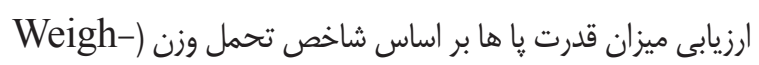

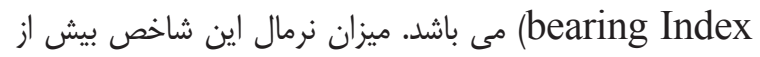

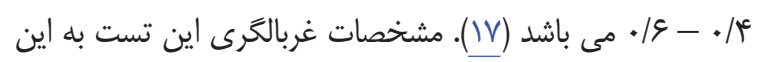

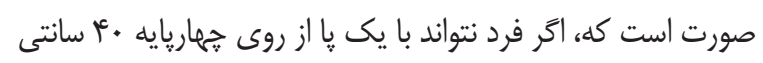


مى دهد (זٓ⿱ז). جهت اندازه كيرى كاهش و افت تحرى و راه رفتن

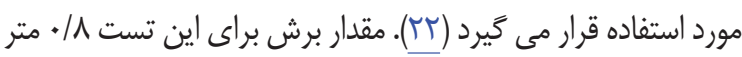

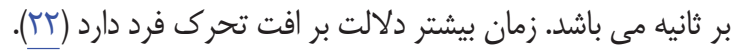

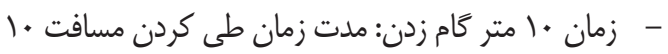

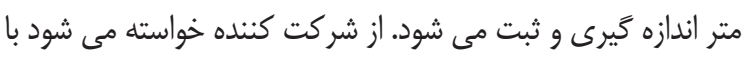

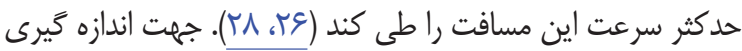

كاهش و افت تحرك و راه رفتن مورد استفاده قرار مى گيرد.

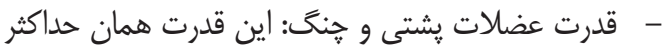

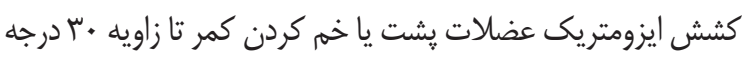
در حالى كه فرد ايستاده است و اين قدرت كشش با استفاده از دستخاه اندازه كيريى و ثبت مى شود. قدرت جنَّ در هر دو دست با استفاده

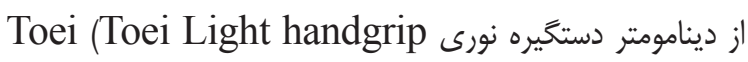
(dynamometer اندازه كَيرى خواهد شد (وَ). براى كرفتن

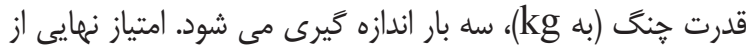

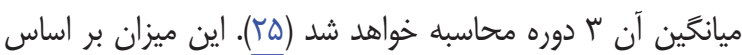
وزن فرد و جنس متفاوت مى باشد (• مبا).

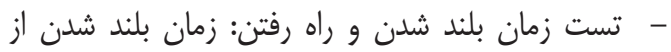

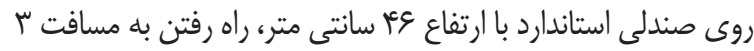

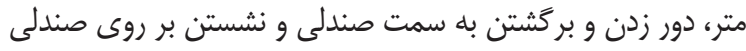

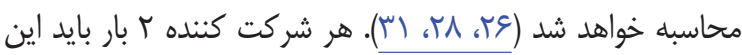
تست را انجام دهد. ميانكَين امتياز ثبت خواهد شد و مورد ارزيابى قرار خواهد كَرفت. شركت كنندكان در اين تست اجازه به يوشيدن

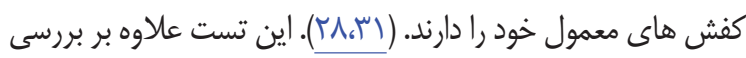

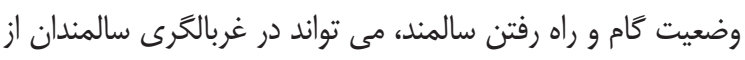

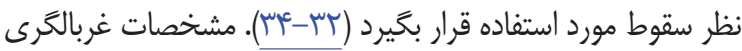
شامل: كوتاهترين زمان (دو مرحله نسبت به هم)، به ثانيه ثبت خواهد شد. مدت زمان كوتاهتر نشان دهنده و دلالت بر انجام بهتر تست

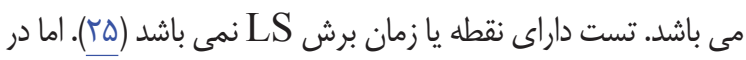
يك مطالعه مجزا، زمان برش براى غربالكَى سقوط در سالمندان،

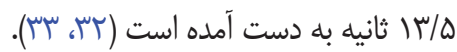
- حدكثر كام: از فرد شركت كننده خواسته مى شود كه در

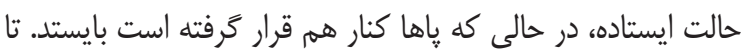

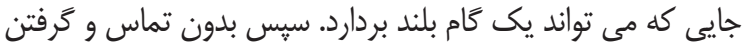

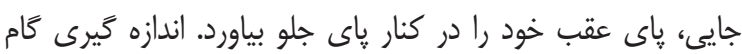

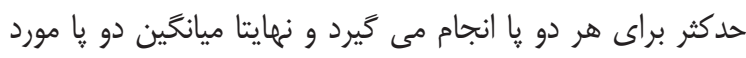

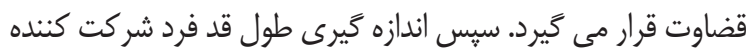
انجام مى كيرد. ميانخين دو يا بر طول قد فرد شركت كننده تقسيم

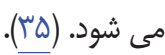

مورد ارزيابى قرار مى گيرد. كاهش زمان تست مى تواند با وقايع منفى همجِون سقوط و كاهش ADL سالمند ارتباط قوى داشته باشد. حدكثر زمان براى نحَه داشتن پا •و ثانيه مى باشد. ميانكَين زمان دو يا ثبت مى كردد. زمان كمتر مساوى ها اثانيه براى سالمند آسيب يذير تلقى مى شود. اما زمان برش داراى بيشترين حساسيت

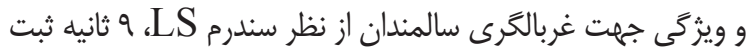

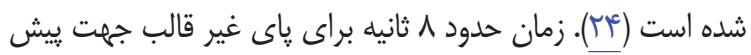
بينى خطر سقوط در جمعيت سالمند مناسب است (بَ).

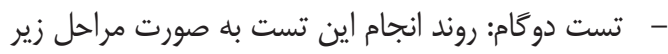
است: ا- تعيين خط شروع و ايستادن فرد با قرار دادن انغشتان ڤيا بر روى و يا ڤشت خط. ז- از فرد خواسته مى شود كه تا جايى كه

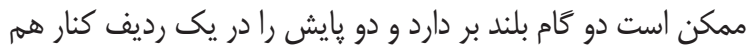

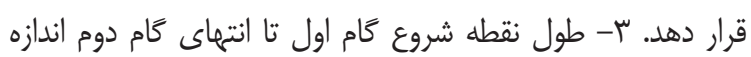
كيرى مى شود. در مرحله آخر در صورتى كه فرد بتواند به مدت

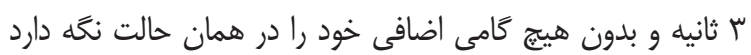

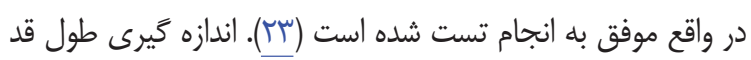

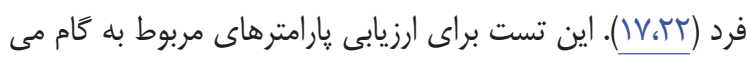

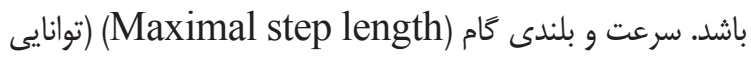
برداشتن بلندترين كام و برَشتن به نقطه ابتدايى) مورد اندازه كَيرى

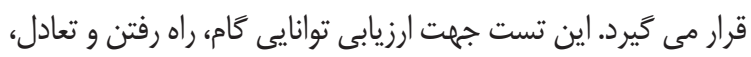

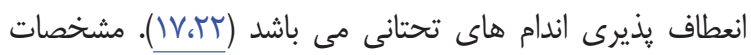

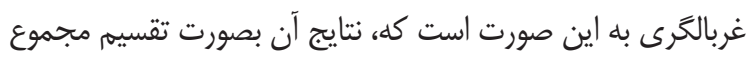

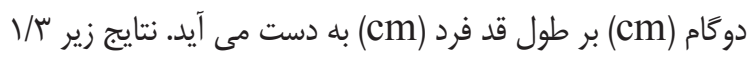

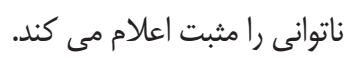
اختلال درجه اول: تست دو كام كمتر از س/ا. اختلال درجه

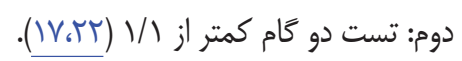

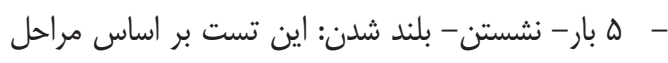

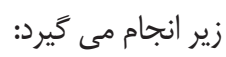
1. استفاده از صندلى كه داراى يشتى باشد. سطح نشيمنكاه

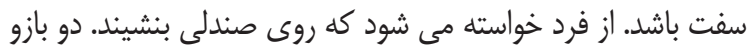
را روى سينه قرار دهد. از او خواسته مى شود تا جايى كه مى تو تواند باند ه مرتبه سريع از روى صندلى بلند شود و بنشيند. زمان انجام مرحله فئه

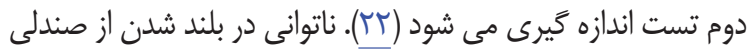

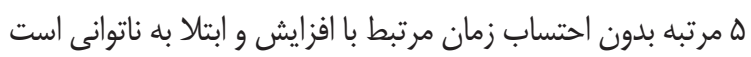

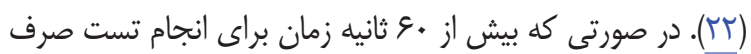

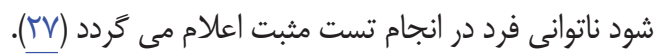

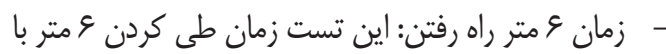

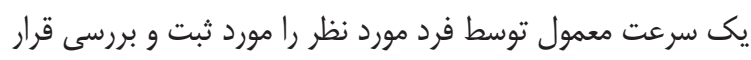


س- ارتباط ابزار هاى غربالكرى با اختلالات حركتى و تبعات

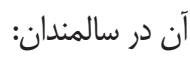

با توجه به مطالعات انجام شده، مى توان نتيجه گرفت كه بين سندرم حركتى و كيفيت زندگى، سقوط، درد، محدوديت و ناتوانى

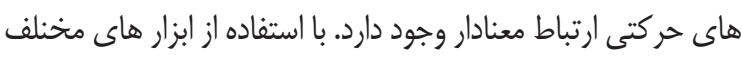

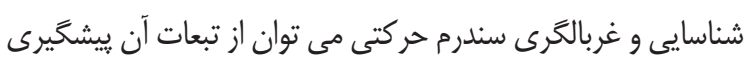

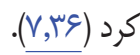

\section{بحث و نتيجه تيرى}

بر اساس نوع مطالعه (مرورى يا كتابخانه ایى)، براى جلوگيرى

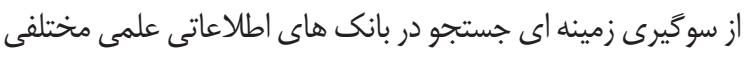
انجام شد. محقق قبل از اين مطالعه، هيج مطالعه اوليه اي در زمينه

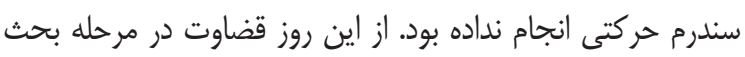
كاملا بى طرفانه و بدون قضاوت انجام كرفت.

مقاله مرورى حاضر با هدف مرورى يكيارجه بر روش هاى

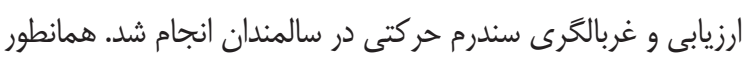
كه ديده شد، براى بررسى و غربالكرى سندرم حركتى از دو روش كلى، تست هاى عملكرد جسمى و يرسشنامه هاى غربالكرى مى توان استفاده كرد. در بررسى تست هاى عملكرد جسمى مى توان كفت، تست هاى عملكردى تنها بعد جسمى را مورد ارزيابى تونى قرار مى دهند، اين در حاليست كه در توانمندى سيستم حركتى

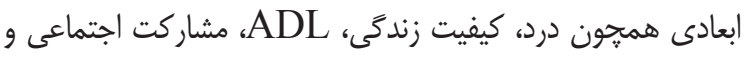
مسايل روانى و فرهنخى نيز قابل بررسى است. از سويى ديخر استفاده از تست هاى عملكردى براى رسيدن به نتايج معتبر بايد بصورت

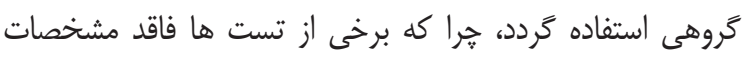
روانسنجى است. تست هاى ايستادن بر روى يكى يا از خهاريايه،

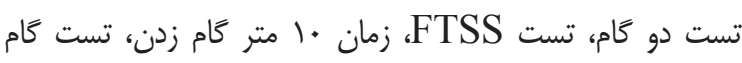
حداكثر، براى ييش بينى سندرم حركتى و ناتوانى ناشى از آن قابل استفاده نيست و فاقد نقطه برش براى غربالكرى سندرم حركتى برى

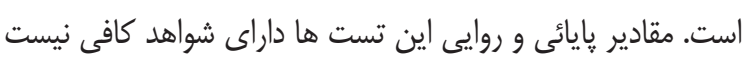

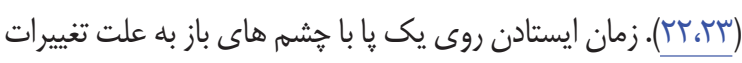

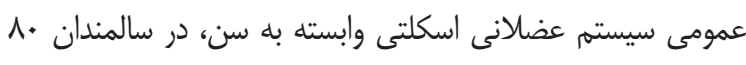

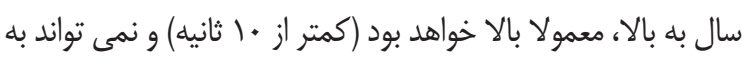
عنوان معيار به تنهايى، در رد يا يذيرش سندرم حر كتى يذيرفته شود.

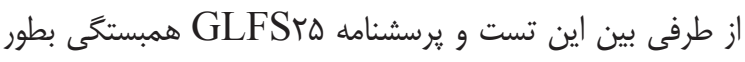

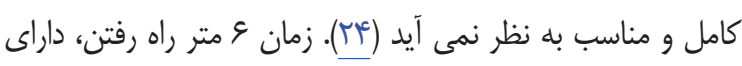

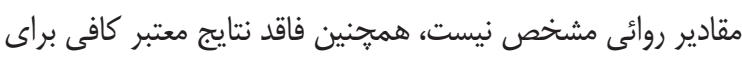

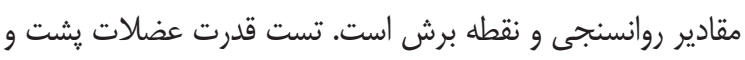

$$
\text { r- پيرسشنامه هاى غربالحرى سندرم حركتى: }
$$
-Loco-Check -

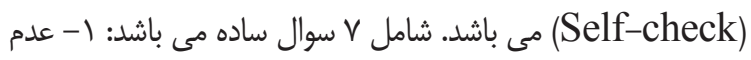
توانايى در يوشيدن جوراب در حالى كه بر روى يك يا ايستاده است.

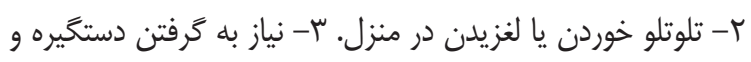
نرده مخصوص براى بالا رفتن از يله ها. أ- مشكل در انجام فعاليت

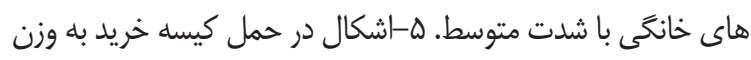
r كيلوگرم از محل خريد تا منزل. צ- مشكل در راه راه رفتن مستمر به مدت ها دقيقه و بيشتر. V- عدم توانايى در عبور از خطوط عابر قبل

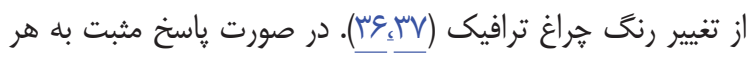

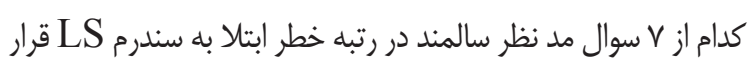

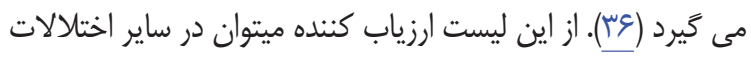

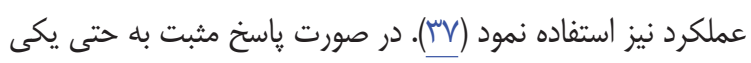
از V سوال ليست، سالمند در كروه مشكوك به سندرم LS قرار

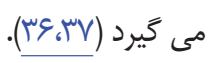
- - يرسشنامه مقياس عملكرد حركتى سالمندى - -هז: اين

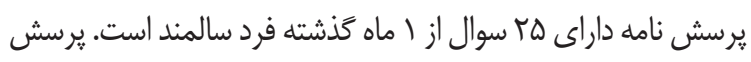

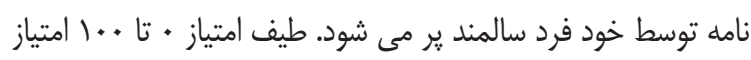

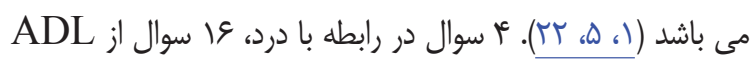

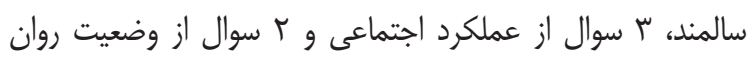

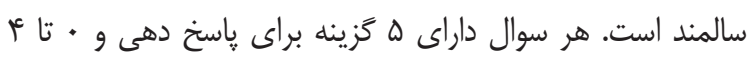

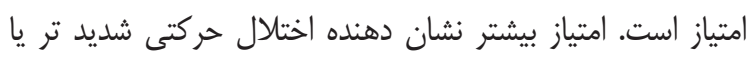

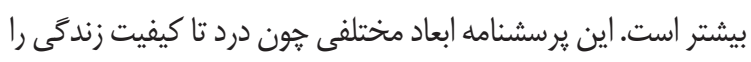

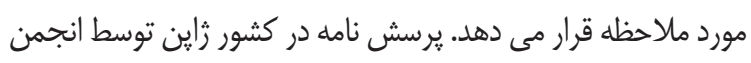
ارتويدى اين كشور تدوين گشته است. اين يرسش نامه براى افراد

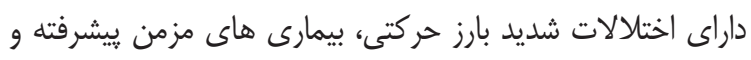

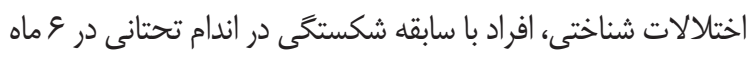

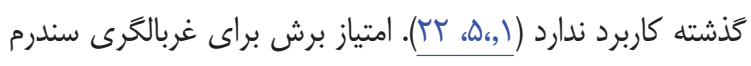
حركتى بر اساس امتيازات اين يرسشنامه عا به بالا مى باشد. افراد

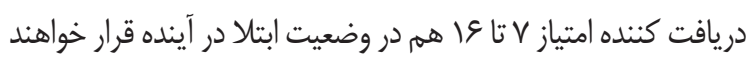

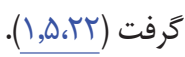

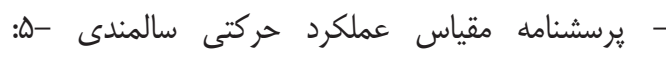

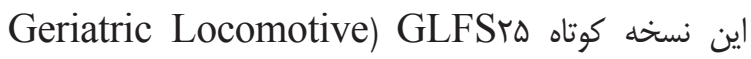
میى باشد. ه سوال از ADL-Function Scale

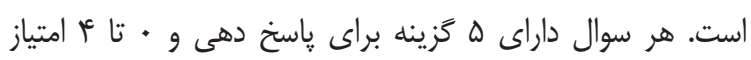

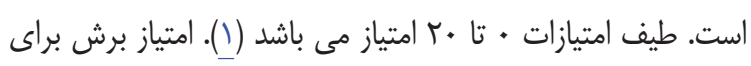

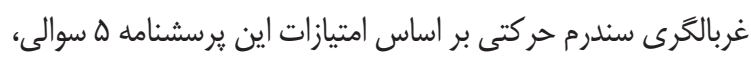

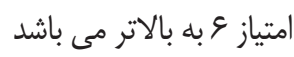


با تحرى (Locomotion)، قدرت بالا در ييش بينى ييامد هاى

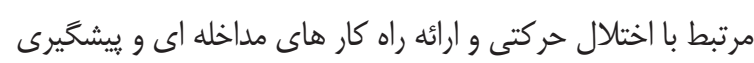

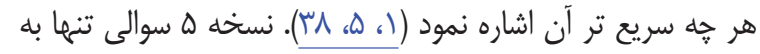
بررسى ADL سالمند مى يردازد. به نظر مى رسد بررسى حيطه

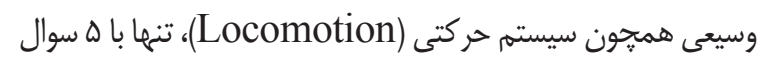
مورد اعتماد نباشد، با اين حال نتايج روانسنجى اين يرسشنامه نشان

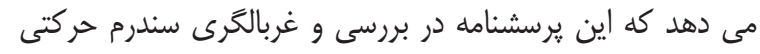

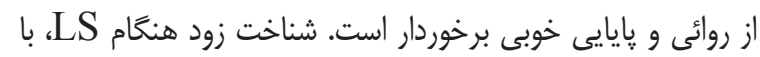

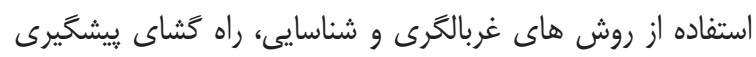

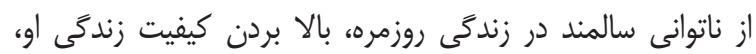
تامين سلامت روانى و بالا بردن مشاركت اجتماعى است (سب). نتايج

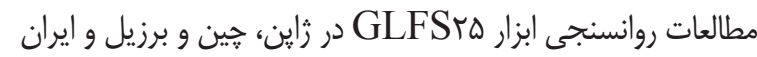

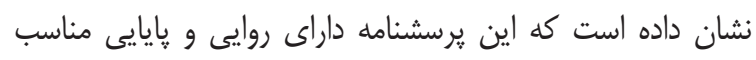
براى گروه سالمندان در معرض خطر LS مى باشد (ا، ه، مب). بنابراين استفاده از روش هاى غربالكرى مناسب با ويزَّيهاى دقيق غربالكرى به منظور شناسايى بموقع سندرم حركتى در سالمندان

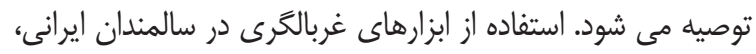

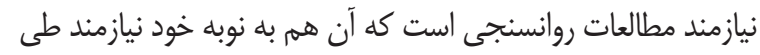
شدن مراحل آمارى و تحليلى است كه در يزوهشى جداتانانه قابل بررسى است.

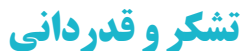

بدين وسيله از اساتيد محترم يرستارى و سالمندى دانشكاه علوم بهزيستى تهران كه محقق را در انجام يثوهش يارى نمودند

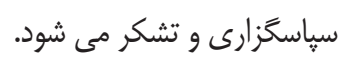

\section{Refrences}

1. Seichi A, Hoshino Y, Doi T, Akai M, Tobimatsu Y, Iwaya T. Development of a screening tool for risk of locomotive syndrome in the elderly: the 25-question Geriatric Locomotive Function Scale. J Orthop Sci. 2012; 17 (2):163-72.

2. Moti-Haghshenas N. Sociological Dimensions of Aging Population and the Challenge of Active Aging in Iran. Sociological Studies of Iran. 2012; 1 (2):133 - 48.

3. Mirzaei M, Mehri S. DEMOGRAPHY OF ELDER POPULATION IN IRAN OVER THE PERIOD 1956 TO 2006. Salmand 2007;2 (5): 326-31.

4. Adib-Hajbaghery M, Aghahoseini S. The
קنغ زدن، داراى مقادير روانسنجى معتبر نيست، فاقد نقطه برش

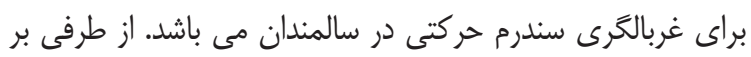

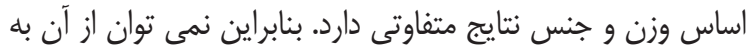
عنوان يك روش معتبر در جمعيت عمومى سالمندان استفاده نمود. تست TUG، داراى مقادير روائى نيست. هم هنين در مطالعات يافت شده، نتايج روانسنجى داراى شواهد كافى نيست. اين تست داري فاقد قابليت دنبال كردن به منظور ييش بينى ناتوانى ناشى از سندرم

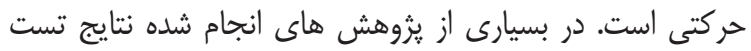

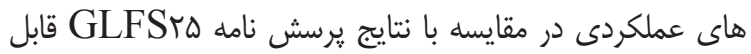

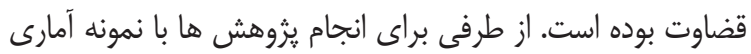
بالا انجام تست هاى غربالكرى هم با صرف بالاى هزينه و زمان همراه است، هم از حوصله فرد سالمند خارج مى باشد و منجر به عدم بام

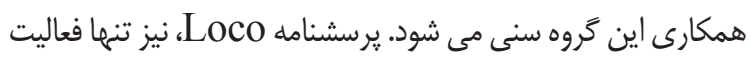
هاى عمومى سالمند را بررسى كرده و فاقد توانائى غربالحرى است. ايعاد اين يرسشنامه قابل تفكيك و تعريف شده نيست. اين برسشنامه فاقد شواهد كافى روانسنجى است و از همين رو توالى منظمى بين آيتم هاى يرسش نامه ديده نمى شود. ارزش كذارى براى آيتم هاى

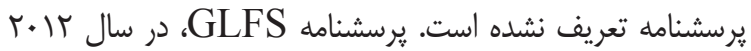
در دو نسخه ه و هT سوالى، توسط انجمن ارتويدى زاين ساخته و

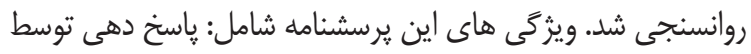

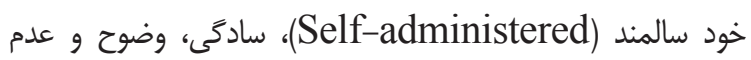
وجود ابهام در سوالات كه منجر به فهم آسان توسط كروه هاى

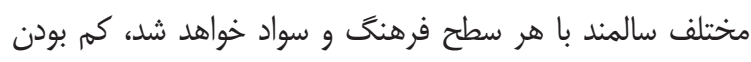

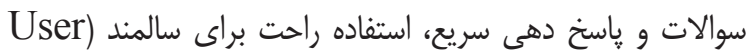

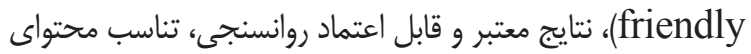
يرسشنامه با مفهوم LS، بررسى ابعاد مختلف جسمى و روانى مرتبط

evaluation of disability and its related factors among the elderly population in Kashan, Iran. BMC Public Health. 2007; 7 (1): 261.

5. Tavares D, Santos F. Locomotive syndrome in the elderly: Translation,cultural adaptation, and Brazilian validation of the tool 25-question Geriatric Locomotive Function Scale. RBR. 2016; 57 (1): 56-63.

6. Gation. JOA new patient survey 2012. Japanese Orthopaedic Association. 2016.

7. Makino T, Kaito T, Yonenobu K. Spinal Disorders as a Cause of Locomotive Syndrome: The Influence on Functional Mobility and Activities of Daily Living. Clinic Rev Bone Miner Metab. 2016; 14 (2): 105-15. 
8. Pollard B, Johnston M. The assessment of disability associated with osteoarthritis. Current Opinion in Rheumatology. 2006; 18 (5): 531-6.

9. Umer W, Antwi-Afari MF, Li H, Szeto GPY, Wong AYL. The prevalence of musculoskeletal symptoms in the construction industry: a systematic review and meta-analysis. International Archives of Occupational and Environmental Health. 2018; 91 (2): 125-44.

10. Schneider EL, Guralnik JM. The aging of america: Impact on health care costs. JAMA. 1990; 263 (17): 2335 - 40.

11. Klussmann A, Gebhardt H, Nubling M, Liebers F, Quiros Perea E, Cordier W, et al. Individual and occupational risk factors for knee osteoarthritis: results of a case-control study in Germany. Arthritis research \& therapy. 2010; 12 (3):R88.

12. Kavita K, Sumer S, Simratjee K. To study the Prevalence of musculoskeletal Disorders and its Influence on Quality of Life in Geriatric Population. indian journal of physiotherapy and occupational therapy-an international journal. 2018;12 (2): 98 - 102.

13. Williams SG. Impact of a growing elderly population on nursing. Nursing forum. 1992; 27 (3): $20-2$.

14. Mirhaghi A-H, Roodbari $M$. the amount of knowledge about hospital triage nurses. journal of critical care nursing. 2010;3 (4): 165 - 70.

15. Maghsoudniya S. Primary Health Care in the Elderly Iran. Tehran: Center for Aging Research: University of Rehabilitation Sciences and Social Welfare; 2015.

16. Sahaf R, Shams A, Fadaye-vatan R, Delbari A, Sabouri M, Mirzaei S, et al. Determine the validity and reliability levels of physical activity (CHAMPS) in elderly Tehrani. Elder. 2015; 9 (3): $206-17$.

17. Nakamura K, Ogata T. Locomotiv Syndrome: Definition and Management. Clinic Rev Bone Miner Metab. 2016; 14 (2): 56-67.

18. Ishijima M, Kaneko H, Hada S, Kinoshita M, Sadatsuki R, Liu L, et al. Osteoarthritis as a Cause of Locomotive Syndrome: Its Influence on Functional Mobility and Activities of Daily Living. Clinic Rev Bone Miner Metab. 2016; 14 (2): 77-104.

19. Sadeghi-Mahalli N, Hoseini m-A, Rahgozar M, Noruzi K. Locomotive Syndrome in Qaemshahr
Elderly and its Risk Factors. Salmand: Iranian Journal of Ageing. 2018;13 (5): 14.

20. Sadeghi-Mahalli N, Noruzi K, Hoseini m-A, Rahgozar M, Kavar S-H. THE RELATIONSHIP BETWEEN LOCOMOTIVE SYNDROME AND QUALITY OF LIFE IN THE ELDERLY. J Evolution Med Dent Sci. 2018; 7 (34): 5.

21. Cochrane-community. Ethical considerations: chocrane; 2018 [Available from: https:// community.cochrane.org/book_pdf/362.

22. Yoshimura N, Muraki S, Oka H, Tanaka S, Ogata $\mathrm{T}$, Kawaguchi H, et al. Association between new indices in the locomotive syndrome risk test and decline in mobility: third survey of the ROAD study. J Orthop Sci. 2015; 20: 10.

23. Ogata $T$, Muranaga $S$, Ishibashi $H$, Ohe $T$, Izumida R, Yoshimura N, et al. Development of a screening program to assess motor function in the adult population: a cross-sectional observational study. Journal of Orthopaedic Science. 2015; 20 (5): 888 - 95.

24. Seichi A, Hoshino Y, Doi T, Akai M, Tobimatsu Y, Kita K, et al. Determination of the optimal cutoff time to use when screening elderly people for locomotive syndrome using the one-leg standing test (with eyes open). J Orthop Sci. 2014; 19: 7.

25. Benavent-Caballer V, Sendin-Magdalena A, Lison JF, Rosado-Calatayud P, Amer-Cuenca JJ, Salvador-Coloma P, et al. Physical factors underlying the Timed "Up and Go" test in older adults. Geriatric nursing (New York, NY). 2016; 37 (2): 122 - 7.

26. Muramoto A, Imagama S, Ito Z, Hirano K, Tauchi $\mathrm{R}$, Ishiguro $\mathrm{N}$, et al. Threshold values of physical performance tests for locomotive syndrome. J Orthop Sci. 2013; 18 (4): 618 - 26.

27. Pinheiro PA, Carneiro JA, Coqueiro RS, Pereira R, Fernandes MH. "Chair Stand Test" as Simple Tool for Sarcopenia Screening in Elderly Women. The journal of nutrition, health \& aging. 2016; 20 (1): 56-9.

28. Hirano $\mathrm{K}$, Imagama $\mathrm{S}$, Hasegawa $\mathrm{Y}$, Ito $\mathrm{Z}$, Muramoto A, Ishiguro N. Impact of low back pain, knee pain, and timed up-and-go test on quality of life in community-living people. JOS. 2014; 19:8.

29. Hirano K, Imagama S, Hasegawa $Y$, Ito Z, Muramoto A, Ishiguro N. Impact of low back 
pain, knee pain, and timed up-and-go test on quality of life in community-living people. J Orthop Sci. 2014;19 (1): 164 - 71.

30. Yoshimura N, Oka H, Muraki S, Akune T, Hirabayashi N, Matsuda S, et al. Reference values for hand grip strength, muscle mass, walking time, and one-leg standing time as indices for locomotive syndrome and associated disability: the second survey of the ROAD study. J Orthop Sci. 2011;16 (6): 768 - 77.

31. Gautschi OP, Corniola MV, Joswig H, Smoll NR, Chau I, Jucker D, et al. The timed up and go test for lumbar degenerative disc disease. Journal of clinical neuroscience: official journal of the Neurosurgical Society of Australasia. 2015; 22 (12): 1943 - 8.

32. Herman T, Giladi N, Hausdorff JM. Properties of the 'timed up and go' test: more than meets the eye. Gerontology. 2011; 57 (3): 203 - 10.

33. Hirase $\mathrm{T}$, Inokuchi $\mathrm{S}$, Matsusaka $\mathrm{N}$, Nakahara K, Okita M. A modified fall risk assessment tool that is specific to physical function predicts falls in community-dwelling elderly people. Journal of geriatric physical therapy (2001). 2014; 37 (4): $159-65$.

34. Vance RC, Healy DG, Galvin R, French HP. Dual tasking with the timed "up \& go" test improves detection of risk of falls in people with Parkinson disease. Physical therapy. 2015; 95 (1): 95-102.

35. Muramoto A, Imagama S, Ito Z, Hirano K, Ishiguro N, Hasegawa Y. Physical performance tests are useful for evaluating and monitoring the severity of locomotive syndrome. JOS. 2012; 17 (6): $782-8$.

36. Iizuka Y, Iizuka H, Mieda T, Tajika T, Yamamoto A, Takagishi K. Association between "lococheck" and EuroQol, a comprehensive instrument for assessing health-related quality of life: a study of the Japanese general population. J Orthop Sci. 2014; 19 (5): 786 - 91.

37. Matsui Y, Takemura M, Harada A, Ando F, Shimokata H. Utility of "loco-check," selfchecklist for "locomotive syndrome" as a tool for estimating the physical dysfunction of elderly people. Health. 2013; 5 (6): 97-102.

38. Ning Z, Rui-li Z, Hui-juan L. Validity and reliability of the Chinese version of Geriatric Locomotive Function Scale. Chinese Journal of Nursing. 2016.
39. Sadeghi-Mahalli N, Hoseini m-A, Rahgozar M, Noruzi K. EVALUATION OF CULTURAL ADAPTATION, VALIDITY AND RELIABILITY OF THE QUESTIONNAIRE OF GERIATRIC LOCOMOTIVE FUNCTION SCALE - 25 QUESTIONS. Pharmacophore. 2017;8 (6s):5.

40. 40. Yoshimura N, Muraki S, Oka H, Tanaka $\mathrm{S}$, Ogata $\mathrm{T}$, Kawaguchi $\mathrm{H}$, et al. Association between new indices in the locomotive syndrome risk test and decline in mobility: third survey of the ROAD study. J Orthop Sci. 2015; 20 (5): 896 $-905$.

41. Seichi A, Hoshino Y, Doi T, Akai M, Tobimatsu Y, Kita K, et al. Determination of the optimal cutoff time to use when screening elderly people for locomotive syndrome using the one-leg standing test (with eyes open). J Orthop Sci. 2014; 19 (4): 620 - 6.

42. Sasaki E, Ishibashi Y, Tsuda E, Ono A, Yamamoto $\mathrm{Y}$, Inoue $\mathrm{R}$, et al. Evaluation of locomotive disability using loco-check: a cross-sectional study in the Japanese general population. J Orthop Sci. 2013; 18 (1): 121 - 9. 